\title{
Optimization and Realization of the Continuous Reactor with Improved Automatic Disturbance Rejection Control
}

\author{
Mingsan Ouyang $(\mathbb{D}$ and Yunlong Wang $(\mathbb{D}$ \\ School of Electrical and Information Engineering, \\ State Key Laboratory of Deep Coal Mining Response and Disaster Prevention and Control, \\ Anhui University of Science and Technology, Process Control Laboratory, Huainan, China \\ Correspondence should be addressed to Yunlong Wang; 2383145234@qq.com
}

Received 26 June 2020; Revised 29 October 2020; Accepted 7 November 2020; Published 23 November 2020

Academic Editor: Guang Li

Copyright (c) 2020 Mingsan Ouyang and Yunlong Wang. This is an open access article distributed under the Creative Commons Attribution License, which permits unrestricted use, distribution, and reproduction in any medium, provided the original work is properly cited.

\begin{abstract}
In the chemical production process, the temperature of the continuous reactor has nonlinear characteristics such as large inertia. An improved autodisturbance control method is proposed. By improving the tracking differentiator with adjustable parameters, the expanded state observer and the control structure obtained an improved automatic disturbance rejection control model and realized the optimal control of the nonlinear and large-delay systems. On the process control training system, the experiment of the continuous system process flow is compared with the anti-interference of the Smith predictive compensation system, which uses an optimal set of data. The reactor temperature fluctuates, but the self-resistance is improved. The optimal overshoot of the disturbance is close to 0 . Compared with the original antidisturbance controller, the antidisturbance time is not affected by the number of iterations, which reduces the high requirements on the accuracy of the parameters. Therefore, the improved automatic disturbance rejection control improves the operation and enhances the ability to resist external disturbance that changes the controlled object.
\end{abstract}

\section{Introduction}

Continuous process reactors are critical to the production quality of chemicals, fuels, and polymers. Owing to the strong coupling and nonlinear characteristics of the reactor, regulation of the system is challenging. Many advanced control strategies have been proposed to control the process. In previous studies [1-4], evolutionary algorithms were used to effectively suppress interference, adjust the temperature of the CSTR, and improve the robustness of the raspberry PI control, event-driven sliding mode control, and fuzzy control. Fuzzy logic plays a key role in diagnosing induction motor faults [5]. Sliding mode control also plays a critical role in suppressing the oscillation of the electric machine system [6]. In previous studies [7, 8], particle swarm optimization technology was used to solve problems in complex linear processes, reduce overshoot percentage, and maintain CSTR temperature at steady-state operating points. Further, the PID controller with predictive components significantly improved the control quality and reduced the maximum deviation of process parameters from the specified value in [9]. In addition, the application of the predictor to the motor drive can improve its reliability [10]. Based on the CONTROL strategy of the PWA model [11], the predictive control algorithm of the display model is adopted to control the system, so as to improve the control efficiency. However, to accurately detect the dangerous state set, the controller that meets the requirements is redesigned to consume time. In another study [12], PID adaptive control was used to track temperature quickly, which has superior control performance; moreover, the application effect of adaptive control method on piezoelectric actuators is useful [13]. In [14], an equivalent adaptive neural network controller was constructed for the CSTR nonlinear model to achieve robust progressive output tracking control and it significantly reduces the control workload. The neural network effectively detects the electrical fault of an asynchronous motor [15]. Based on the model predictive control (PFC) and 
conventional PID method, PPFC [16] is proposed to solve the irregular control problem of the fuzzy prediction algorithm, which is highly dependent on the conventional PID control temperature. The improved Smith prediction controller can improve the anti-interference ability; however, the control effect is not ideal if the system model parameters vary significantly [17]. The robust PID controller has specific antinoise and interference capabilities. When the problem is complex, a large amount of calculation is required, and the calculation time cannot be ignored [18]. In [19, 20], the methods of backward step sliding mode adjustment and control vector iteration were adopted $[19,20]$; however, the precise mathematical model of the system is yet to be determined for this method.

In order to meet the requirements of stable operation, automatic disturbance rejection control (ADRC) has a useful control effect on complex systems with nonlinear characteristics and can automatically compensate for various disturbances [21]. In the forced cycle evaporator, active disturbance suppression [22] solves the robustness of the factory model mismatch. A simple and transparent adjustment and rough process model can meet the design requirements; however, the overshoot quantity is not ideal. Therefore, an improved continuous ADRC temperature control system is proposed in this paper. Under the background of a continuous industrial reaction process, the control effect was compared with that of the Smith PID controller and the original ADRC simultaneously; a significant control effect was achieved.

\section{Improve the Principle of Automatic Disturbance Rejection and Its Control Method for the Reactor}

2.1. Original Automatic Disturbance Rejection Control. The automatic disturbance rejection control compensates for the total disturbance inside and outside the system through a feedforward method and has reasonable control over uncertain objects. Tracking differentiator TD, extended state observer ESO, and nonlinear error feedback control law are the main parts of the control structure [23]. The framework of the automatic disturbance rejection control system is shown in Figure 1.

2.1.1. The Main Mechanism of the Tracking Differentiator (TD). Input the signal $v$ to the tracking differentiator TD, which outputs the tracking input signal $x_{1}$ and the differential form of the input signal $x_{2}$. Its discrete expression is as follows:

$$
\left\{\begin{array}{l}
x_{1}(k+1)=h x_{2}(k)+x_{1}(k), \\
x_{2}(k+1)=h \operatorname{fst}\left(x_{1}(k)-v(k), x_{2}(k), r, h_{0}\right)+x_{2}(k) .
\end{array}\right.
$$

Here, $h$ is the sampling period; the tracking rate is significantly affected by the speed factor $r$; the filtering efficiency of the noise is affected by the filter factor $h_{0}$; fst $\left(x_{1}\right.$, $\left.x_{2}, r, h\right)$ is the most rapid control synthesis function. The principle formulas are as follows:

$$
\left\{\begin{array}{l}
d=r h ; d_{0}=h d ; y=x_{1}+h x_{2}, \\
a_{0}=\left(d^{2}+8 r|y|\right)^{(1 / 2),} \\
a= \begin{cases}x_{2}+\frac{a_{0}-d}{2} \operatorname{sign}(y), & |y|>d_{0}, \\
x_{2}+\frac{y}{h}, & |y| \leq d_{0},\end{cases} \\
\text { fst }\left(x_{1}, x_{2}, r, h\right)= \begin{cases}-r \cdot \operatorname{sign}(a), & |a|>d, \\
-r \cdot \frac{a}{d}, & |a| \leq d .\end{cases}
\end{array}\right.
$$

Here, sign $(\cdot)$ is a symbolic function. TD quickly tracks the input signal without overshooting and outputs a highquality differential signal.

2.1.2. The Extended State Observer. ESO can observe and compensate for the nonlinear dynamics, model uncertainty , and external disturbance in real time. It has reasonable adaptability and robustness. The design takes

$$
f a l(x, \alpha, \delta)= \begin{cases}\frac{x}{\delta^{(1-\alpha)}}, & |x| \leq \delta, \\ \operatorname{sign}(x) \cdot|x|^{a}, & |x|>\delta .\end{cases}
$$

The ESO algorithm is as follows:

$$
\left\{\begin{array}{l}
e(k)=z_{1}(k)-y(k), \\
z_{1}(k+1)=z_{1}(k)+h\left(z_{2}(k)-\beta_{1} e(k)\right), \\
z_{2}(k+1)=z_{2}(k)+h\left(z_{3}(k)-\beta_{2} \mathrm{fal}\left(e, \alpha_{1}, \delta\right)+c u\right), \\
z_{3}(k+1)=z_{3}(k)-\beta_{3} \mathrm{fal}\left(e, \alpha_{2}, \delta\right) .
\end{array}\right.
$$

Here, $h$ is the step size, and $\beta_{1}, \beta_{2}$, and $\beta_{3}$ are a set of adjustable parameters, respectively.

2.1.3. Nonlinear Error Feedback Control Law. The signals generated by TD and ESO successively undergo differential operation to obtain error signal $e_{1}$ and error differential signal $e_{2}$ and then undergo nonlinear combination operation. The result of the operation is the actual control amount of the controlled object and the input amount of ESO. The algorithm is as follows:

$$
\left\{\begin{array}{l}
e_{1}=x_{1}(k)-z_{1}(k), \\
e_{2}=x_{2}(k)-z_{2}(k), \\
u_{0}=k_{p} \cdot \operatorname{fal}\left(e_{1}, \alpha_{1}, \delta\right)+k_{d} \cdot \operatorname{fal}\left(e_{2}, \alpha_{2}, \delta\right), \\
u(k)=\frac{u_{0}-z_{3}(k)}{b}
\end{array}\right.
$$




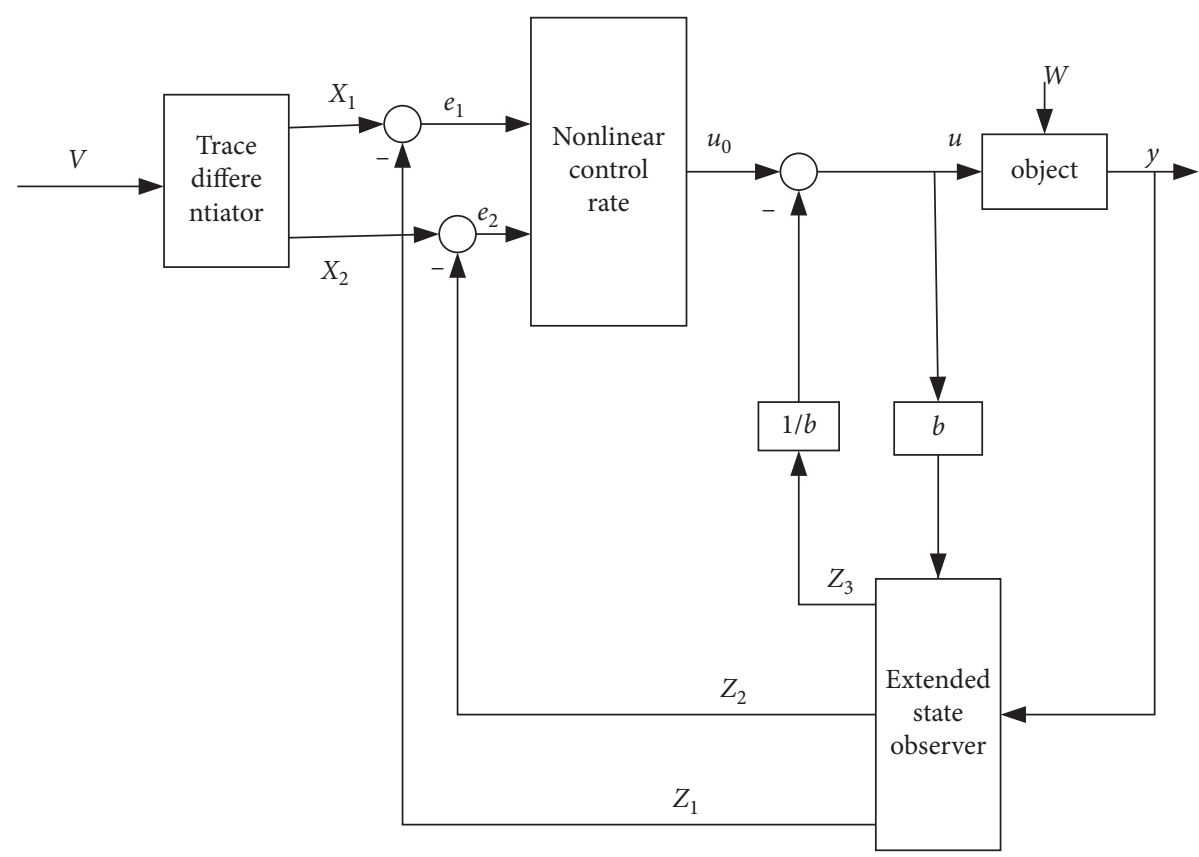

FIGURE 1: Structure of automatic disturbance rejection control system.

Here, $\alpha_{1}, \alpha_{2}, \delta, k_{p}, k_{d}$, and $b$ are all adjustable parameters. A reasonable choice of size can make them realize nonlinear control together.

\subsection{Improved Automatic Disturbance Rejection Control.} The components of the improved automatic disturbance rejection control are the same as those of the original one. The calculation results of the original autodisturbance rejection tracking differentiator and the expanded state device are significantly affected by the number of iterations, resulting in limited signal tracking and internal and external disturbance compensation. The nonlinear combination requires higher accuracy for parameters $k_{p}$ and $k_{d}$, which makes the autoimmunity performance more dependent on parameters $k_{p}$ and $k_{d}$. The improved automatic disturbance rejection control is as follows:

(1) The main mechanism of the tracking differentiator is the same as the original autodisturbance rejection, and its discrete expression is

$$
\left\{\begin{array}{l}
x_{1}(k+1)=h x_{2}(k)+x_{1}(k), \\
x_{2}(k+1)=h \mathrm{fst}\left(x_{1}(k)-v(k), x_{2}(k), r, h_{0}\right)+x_{2}(k) .
\end{array}\right.
$$

Here, the functions of $h, r$, and $h_{0}$ are the same as those in the original antidisturbance tracking differentiator; the function is also the same as above, described as follows:

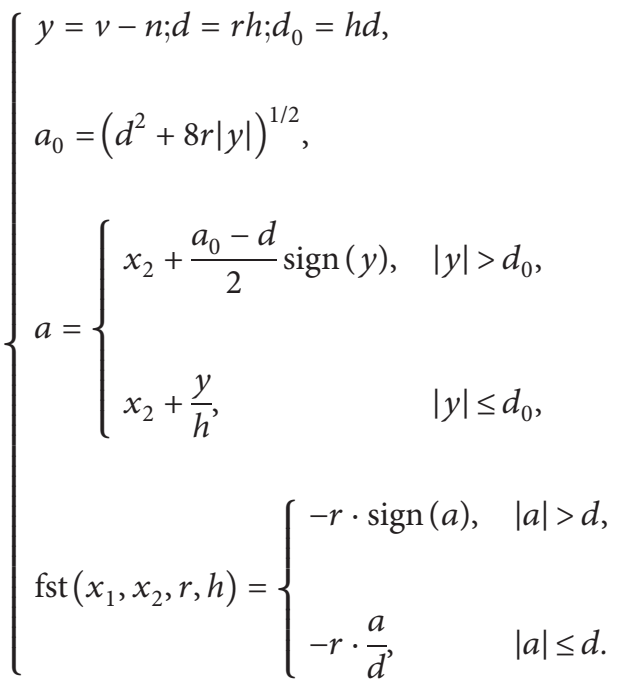

This formula is the same as that for the original automatic disturbance rejection control and has a change in the value, that is, the input signal minus a set value $n$.

(2) The expanded state observer is the most important module that affects the effect of automatic disturbance rejection control. It is improved by referring to the observer proposed by Han Jing-Qing. In the original $e(k)=z_{1}-y(k)$, the input signal is reduced by a set constant; take 


$$
f a l(x, \alpha, \delta)= \begin{cases}\frac{x}{\delta^{(1-\alpha)}}, & |x| \leq \delta, \\ \operatorname{sign}(x) \cdot|x|^{a} & |x|>\delta .\end{cases}
$$

The improved ESO algorithm is as follows:

$$
\left\{\begin{array}{l}
e=v-m \\
\dot{z}_{1}=z_{2}-\beta_{1} e(k) \\
\dot{z}_{2}=z_{3}-\beta_{2} \mathrm{fal}\left(e, \alpha_{1}, \delta\right)+c u \\
\dot{z}_{3}=-\beta_{3} \mathrm{fal}\left(e, \alpha_{2}, \delta\right) .
\end{array}\right.
$$

Here $m$ is a constant according to the requirements of the objects in the project file $v \neq z_{1}$. Processing formula (8), because $\delta>0$, when $x=\delta$, fal $(e, \alpha, \delta)=$ $x / \delta^{(1-\alpha)}=\operatorname{sign}(x) \cdot|x|^{\alpha}=\delta^{\alpha}$, when $x=-\delta$, fal $(e, \alpha, \delta)=$ $x / \delta^{(1-\alpha)}=\operatorname{sign}(x) \cdot|x|^{\alpha}=-\delta^{\alpha}$. The entire function is continuous, and the value of the function increases as $x$ increases.

(3) Design a controller according to the nonlinear error feedback control law: The improved TD and ESO can generate the error signal $e_{1}$ and error differential signal $e_{2}$ of the transition process. Let $e_{1}, e_{2}$, and $z_{3} / b$ be the input signals of the controller. The algorithm of the controller design is as follows:

$$
\left\{\begin{array}{l}
e_{1}=x_{1}(k)-z_{1}(k), \\
e_{2}=x_{2}(k)-z_{2}(k), \\
u_{0}=k_{p} \cdot \mathrm{fal}\left(e_{1}, \alpha_{1}, \delta\right)+k_{d} \cdot \mathrm{fal}\left(e_{2}, \alpha_{2}, \delta\right), \\
u(k)=\frac{u_{0}-z_{3}(k)}{B} .
\end{array}\right.
$$

With this improvement, the autointerference immunity time may become insensitive to the number of iterations; in addition, the accuracy of parameters $k_{p}$ and $k_{d}$ is relatively low. Autoimmunity is also relatively enhanced. The improved automatic disturbance rejection control structure is shown in Figure 2.

2.3. Control Method of the Reactor. According to the improved autodisturbance rejection principle, the continuous reactor is selected as the control object, the reactor temperature is the control variable, the cold-water flow of the condensate pipe is the operation amount, the temperature signal is collected by the tracking differentiator and the expansion observer, and then the tracking differentiator responds. Meanwhile, the expanded state observer estimates the state of the continuous reactor and compensates for internal and external disturbances in the reactor temperature system. The nonlinear error feedback controller combines the difference signals obtained by the tracking differentiator and the expanded state observer through a nonlinear combination as the actual control signal of the system to control the amount of cold-water flow.

\section{Process Based on PCS7 System and Simulation Implementation}

3.1. Process Flow Requirements. The general continuous reaction process mainly includes a storage tank, reactor, flash tank, and condensate tank. A diagram of the continuous reaction process flow control system is shown in Figure 3.

In Figure 3, the labels read as follows: V101: mixing tank, R101: reactor, V102: flash tank, V103: condensation tank, E102: condenser, P101, P102, P103, P105: transfer pump, P104: vacuum pump, FV1101 FV1108, FV1201 FV1203, XV1101, XV1102, XV1105, PV1101 and PV1102: valves, CWS: cold-water end, and LS: hot-water end.

\subsection{Process Requirements}

(1) Raw materials A and B enter the mixing tank V101 at a ratio of $3: 1$. When the $\mathrm{V} 101$ liquid level is a certain amount, the catalyst is added to the reactor.

(2) The reactor R101 liquid level reaches a certain amount, and heating steam is introduced. At this time, the reactor material begins to heat up and induces a reaction. When the temperature reaches a certain condition, heating is stopped. The raw materials undergo chemical reactions to produce products and by-products, release a lot of heat energy, and, at the same time, control the cold-water flow of the condenser. The pressure and temperature of the entire reaction process meet the conditions of being not higher than $150 \mathrm{kPa}$ and $80-120^{\circ} \mathrm{C}$.

(3) Before flashing, the pressure in the flash tank V102 is reduced to $20-40 \mathrm{kPa}$ through the vacuum pump P104 and the valve PV1102 at the top; then, the tank is closed. After the liquid in the reactor flows into the flash tank to purify raw material $A$ in the mixed product, the pressure of the flash tank must be $20-70 \mathrm{kPa}$.

(4) The material A gas in the flash tank flows into the mixing tank V101 through the condensation process to participate in the reaction.

(5) The mixture in the flash tank V102 flows out from the bottom and is purified and refined. It is required to obtain a product with a concentration of $79 \%$ and above (AI1101) and a stable flow rate.

3.3. System Start-Up Configuration. The process flow meets the requirements of Section 3.1 and changes the driving state according to the transfer conditions. When the measured value reaches the set value, the disturbance-free switch is automatic. The start-up sequence SFC is configured according 


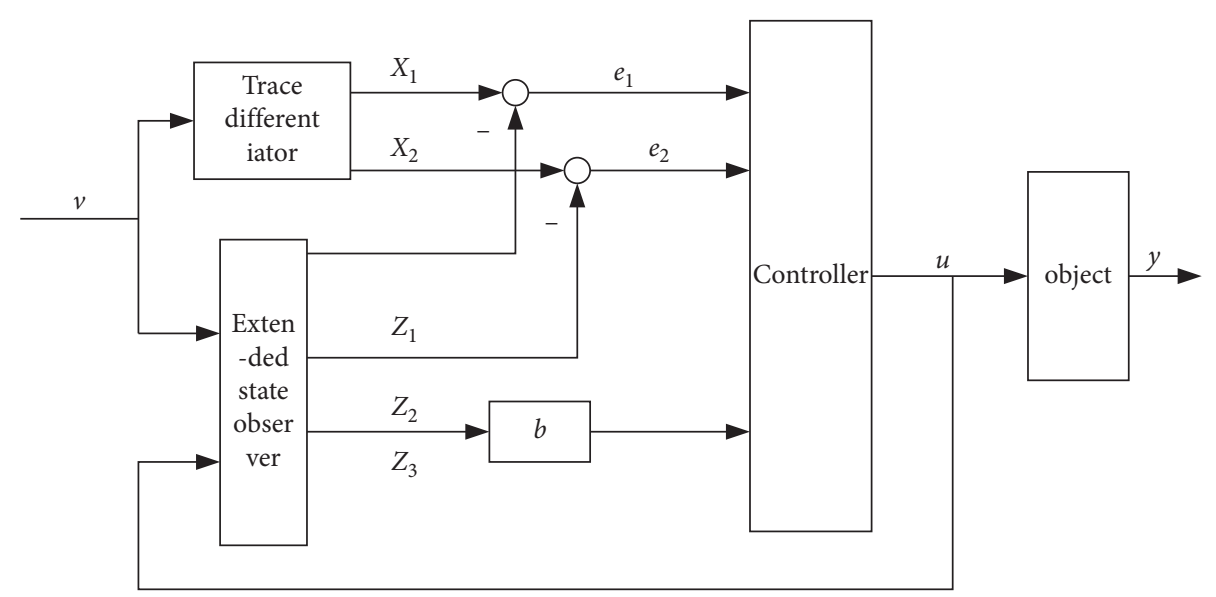

FIgURE 2: The structure of the improved automatic disturbance rejection control system.

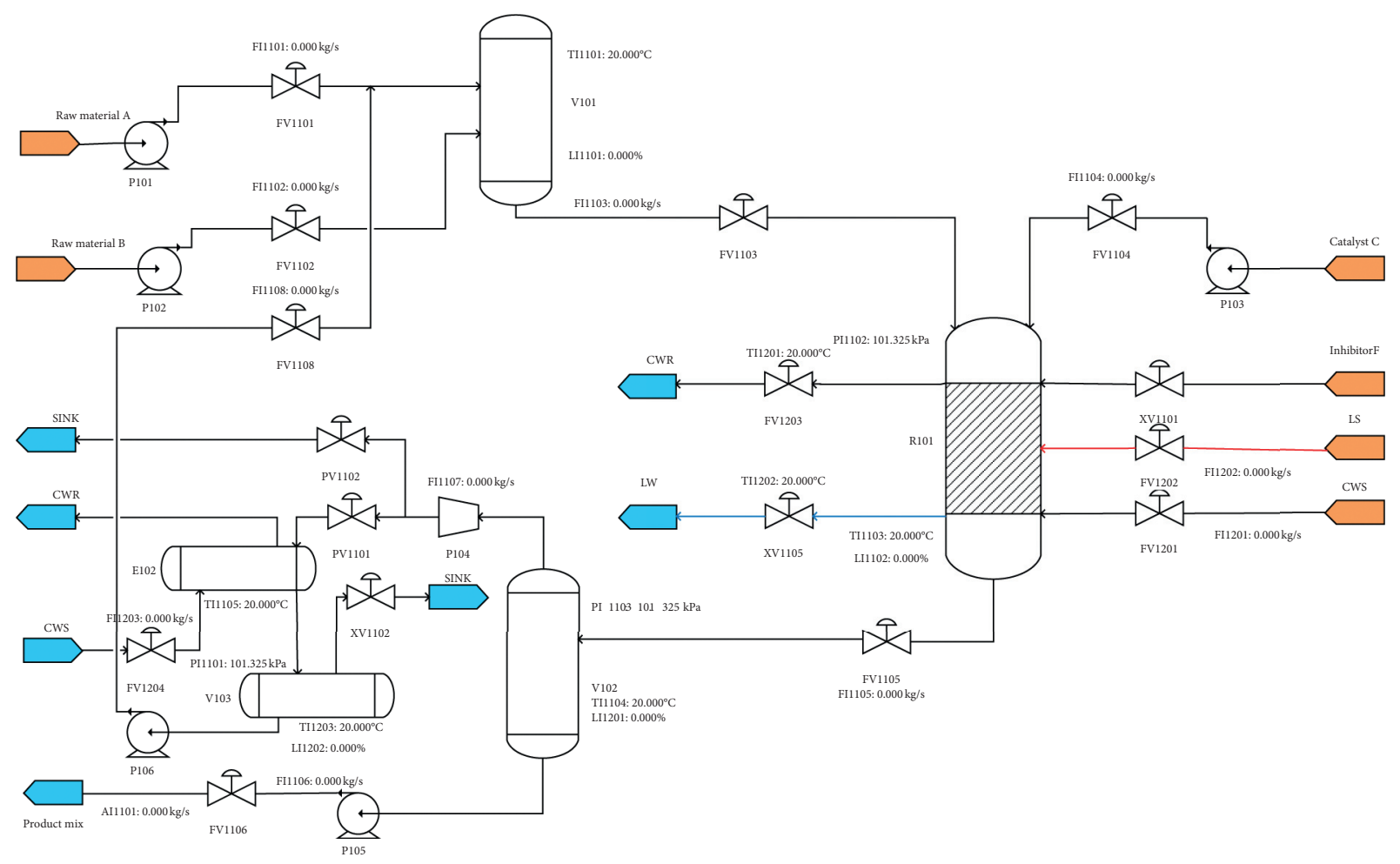

FIGURE 3: Continuous reaction process control system diagram.

to the requirements of process flow in Figure 3. The driving sequence SFC configuration is shown in Figure 4.

The white modules marked with numbers in the figure are unconditional judgments. The configuration content of Figure 4 is as follows:

(1) At the beginning of the start-up, first open the vacuum pump P104 and valve PV1102, reduce the pressure of V102 in the flash tank to atmospheric pressure, such as $20-40 \mathrm{kPa}$, and then close it.
(2) Open the valves FV1101 and FV1102, the liquid level of the storage tank V101 rises to a certain height, and the V101 is automatically controlled.

(3) Open the valves FV1103 and FV1104, feed-stock the reactor, react slowly, and the temperature rises; adjust the cold-water valve FV1201 and hot-water valve FV1202; when the temperature rises to a certain temperature, the reactor temperature is switched to automatic control; the material at the bottom of the reactor is then driven into the flash 


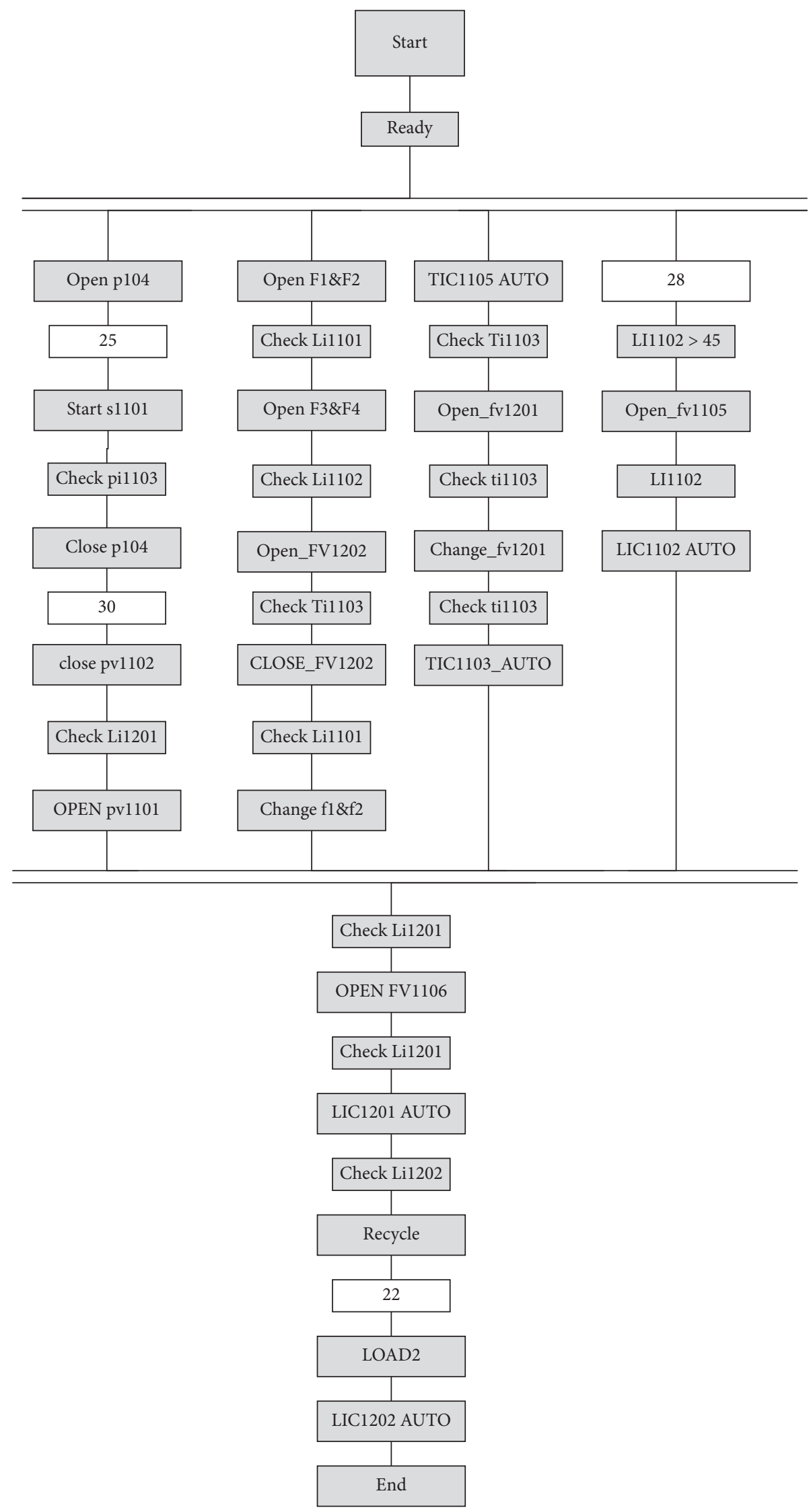

FIgURE 4: SFC driving sequence diagram. 
tank. At this time, it may not be flashed yet. As the temperature rises, it starts to flash (shown as the pressure of the flash tank starts to increase).

(4) When the flash tank starts to flash, open P104 and valve PV1101 again and adjust them. When the pressure of the flash tank reaches a certain value, the pressure is switched to automatic control, and the product flows out through pump P105 and valve FV1106. At the same time, the gaseous phase mainly produced by flash vaporization is introduced into the condenser, and then it becomes liquid and enters the condensing tank. It is pumped into the mixing tank through the circulating pump P106 and valve FV1106. When the condensing tank reaches a certain level, it will condense. The condensation tank is automatically controlled.

(5) After all the tanks are switched to automatic, the load is added to increase the flow rate of the entire production and enhance the throughput.

During the production process, the reactor temperature significantly affects the quality of the product. Because of the nonlinear characteristics of temperature, there are many external uncertain disturbance factors. It is challenging for general controllers to control stability; in addition, the temperature determines the pressure. Therefore, the temperature stability of the reactor is more important. The reactor temperature TI1103 stability is the key.

\subsection{Implementation of the Improved Autoimmunity Principle.} Following the above improvement principle and using SCL language, we develop an algorithm in the Siemens process control system to generate a tracking differentiator (TD), extended state observer (ESO), and controller module. Then, we connect these generated modules with the continuous process reactor temperature signal module. The continuous function chart (CFC) language is written to achieve improved automatic disturbance rejection control and to complete the improved active disturbance rejection loop, as shown in Figure 5.

We have the following: TI1103 module: reactor temperature collector; TD module: tracking differentiator; ESO module: state observer; Subtractor module: subtractor; Multiplier module: multiplier; Controller: nonlinear controller; FV1201 module: cold-water end valve; FV1202 module: hot-water end valve.

The content of the entire CFC loop is as follows: TI1103 collects the reactor temperature signal and then sends it to TD and ESO at the same time. After the TD and ESO modules are calculated, the output signal of TD and the two sets of output signals of ESO are calculated by the adder, and the output value is taken as the input of the nonlinear controller; another set of signals output by the ESO is calculated through the multiplier, and its output value is also used as the input of the nonlinear controller. The nonlinear controller controls the opening of the cold-water valve and the hot-water valve to realize the improved automatic disturbance rejection control of the continuous reactor.

After the continuous function chart is completed, the reactor part in the SFC start-up process configuration in Figure 4 calls the CFC control mode.

\section{Analysis of System Operation Results}

The simulation experiment was implemented using SMPT1000. The control methods and control parameters of the storage tank, flash tank, condensation tank, and the SFC startup sequence were the same in all experiments; the time was set as $40 \mathrm{~min}$. The experimental object in Figures 6-13 is the same project file. For results of operation, Figures 6, 10, and 11 are the improved ADRC for the same set of experimental data; Figures 7 and 8 are the original ADRC with iteration times of 1000 and 4000, respectively; Figure 9 is Smith's estimated compensation control; Figures 11-13 are improved automatic disturbance rejection control experiments with different $k_{p}$ and $k_{d}$ values (Figures 11 and 12 are only different for $k_{d}$, Figures 12 and 13 are only different for $k_{p}$, and Figures 11 and 13 are different for $k_{p}$ and $k_{d}$ ). Among them, Figures 6-8 in Section 4.1 prove that the improved ADRC time is not affected by the number of iterations, and the effect of suppressing oscillation is obvious; Figures 9 and 10 in Section 4.2 further prove the superior anti-interference performance of the improved ADRC. Figures 11-13 in Section 4.3 verify the lower accuracy requirements of $k_{p}$ and $k_{d}$ for improved autodisturbance rejection.

\subsection{Comparative Analysis of the Improved Autodisturbance} Rejection and the Original Autodisturbance Rejection. The experiment uses a better set of data, differentiator parameters, $\alpha=1.0, h=5.0$, and $m=10$, extended observer parameters, $\beta_{1}=100, \beta_{2}=300, \beta_{3}=1000, \delta=0.0025, \alpha_{1}=0.5, \alpha_{2}=0.25$, $n=10$, and $c=1$, and parameters in the nonlinear combination controller, $\delta=0.02, k_{p}=200, k_{d}=20$, and $b=0.06$. The trend curve of the liquid level and pressure of each tank in the process flow is as follows (Figure 6 shows the improved automatic disturbance rejection control (ADRC); Figures 7 and 8 show the original automatic disturbance rejection control with 1000 and 4000 iterations, respectively).

In Figure 6, the first load changed from initial 53 to 80 at $650 \mathrm{~s}$; the second load at about $1000 \mathrm{~s}$ was 83 ; the maximum reactor temperature was 109.741 ; the TI1103 was stabilized at 109.633; the overshoot was 0.000985 , which is close to 0 ; the pressure was PI1102, It is stable at 132.306; the overshoot was about 0.0002796 , and it remained stable after $1700 \mathrm{~s}$.

It can be seen from the iteration of the principle of autodisturbance rejection that the original antijamming control is limited by time. Figures 7 and 8 show the trend graphs of the iteration numbers 1000 and 4000, respectively; the TI1103 autodisturbance rejection times for these cases are $20 \mathrm{~s}$ and $38 \mathrm{~s}$. The set number of iterations is different, and the autointerference rejection time is also different. Owing to the limitation of the number of autointerference- 


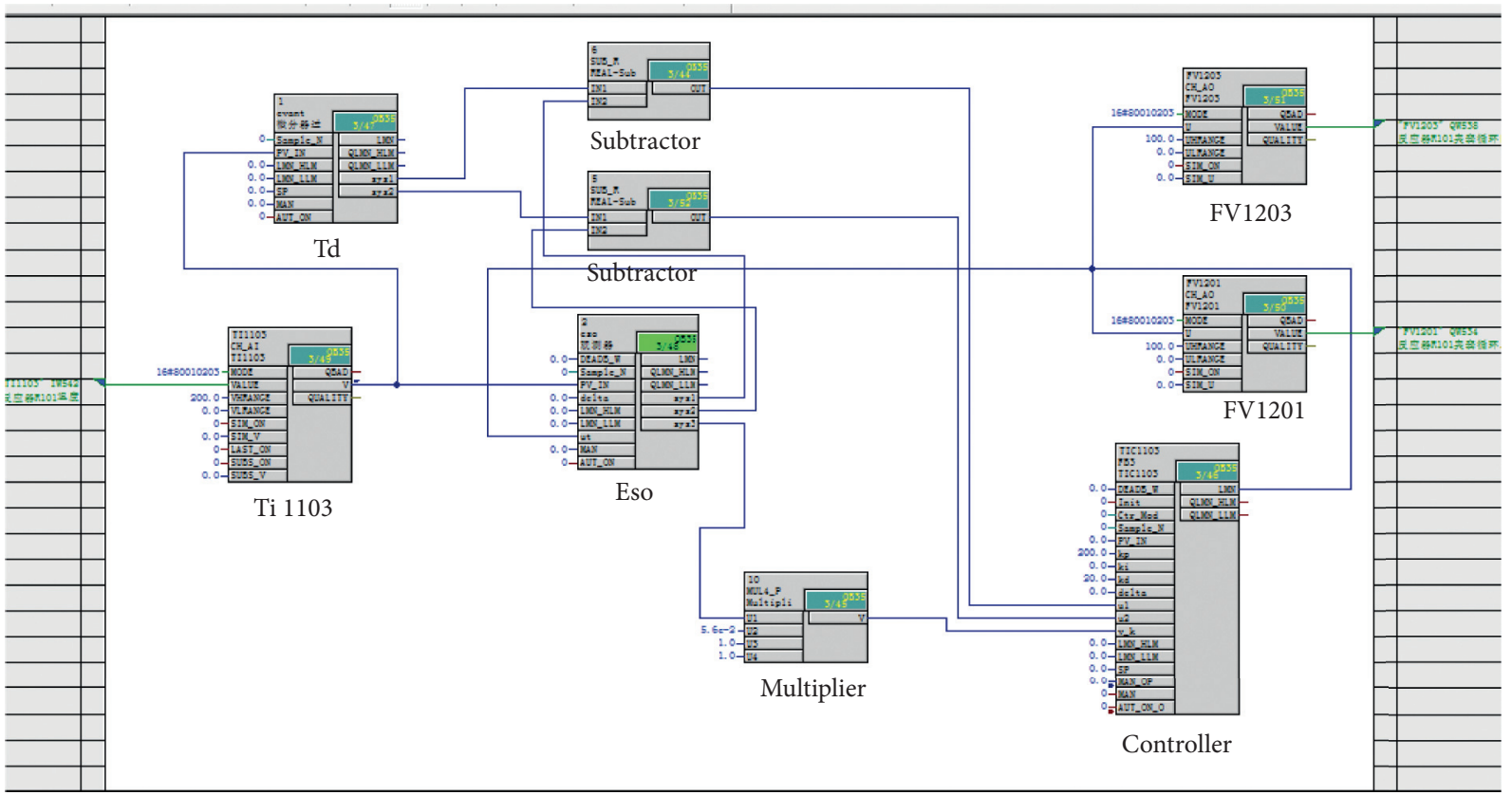

FIGURE 5: Improved autodisturbance rejection principle CFC diagram.

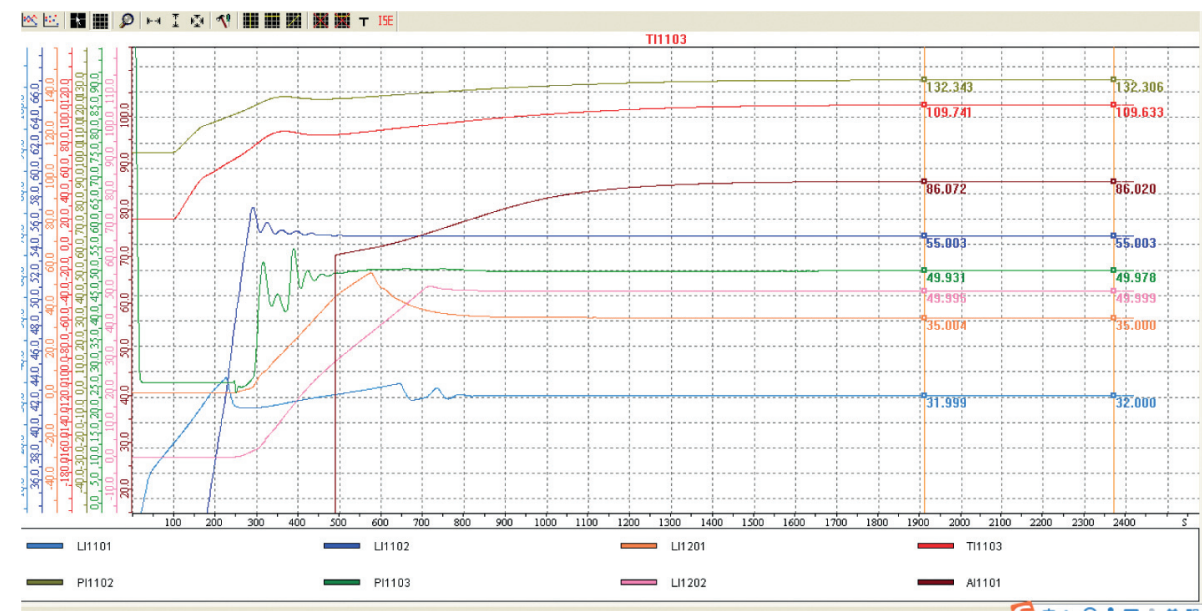

FIGURE 6: Trend graph of improved automatic disturbance rejection control.

free iterations, after the number of iterations, the reactor loses its anti-interference function, and the entire production eventually ends.

Figures 7 and 8 show that the original ADRC is affected by the number of iterations, and the anti-interference time is limited. Contrarily, the improved ADRC shown in Figure 6 is not affected by the number of iterations; in addition, it has a significant effect of suppressing oscillations.

\subsection{Comparative Analysis of Smith's Estimated Compensation} and Improved Autodisturbance Rejection Experiment. Smith estimated the compensation controller from the PCS7 library file. Figure 9 shows the optimal data set for the experimental results. Figures 6 and 10 use the same set of improved autoimmunity data.

Figure 9 shows that the temperature of TI1103 in the Smith estimated compensation system fluctuates between
92.083 and 102.483; the fluctuation range is about 10. PI1102 fluctuates between 126.539 and 129.984; the fluctuation range is about 4.5 .

Comparing Figures 9 and 10, we obtain the following: the Smith estimated compensation controller predicts that the compensation anti-interference performance is inferior in quality to the improved autoimmunity; the stability of the pressure and temperature of the reactor affects the liquid level of the flash tank, condensation tank, stability of the pressure, and product flow AI1101. Therefore, the AI1101 yield flux concentration 86 produced by the autoimmunity is higher and more stable than the Smith yield concentration 82.

4.3. Simulation Analysis of Some Parameter Accuracy Reduction. Analysis and improvement of the principle of autodisturbance rejection, $k_{p}, k_{d}$ accuracy requirements are 


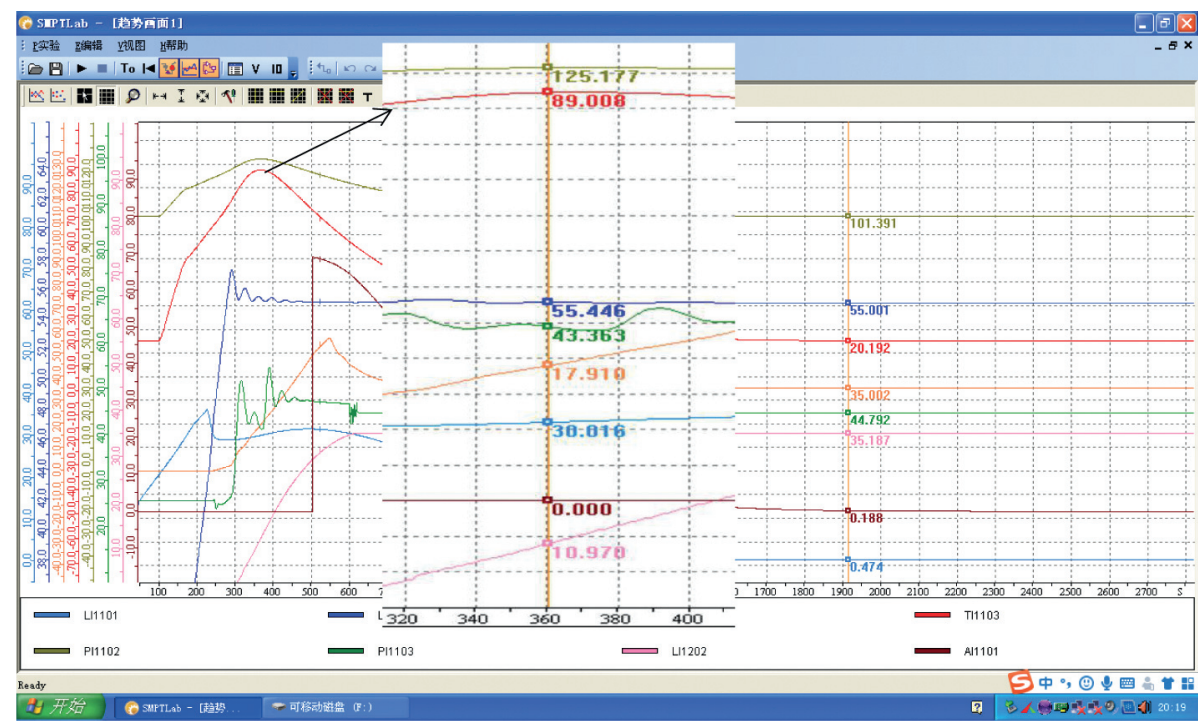

Figure 7: Original automatic disturbance rejection control iteration number 1000 of system trend graph.

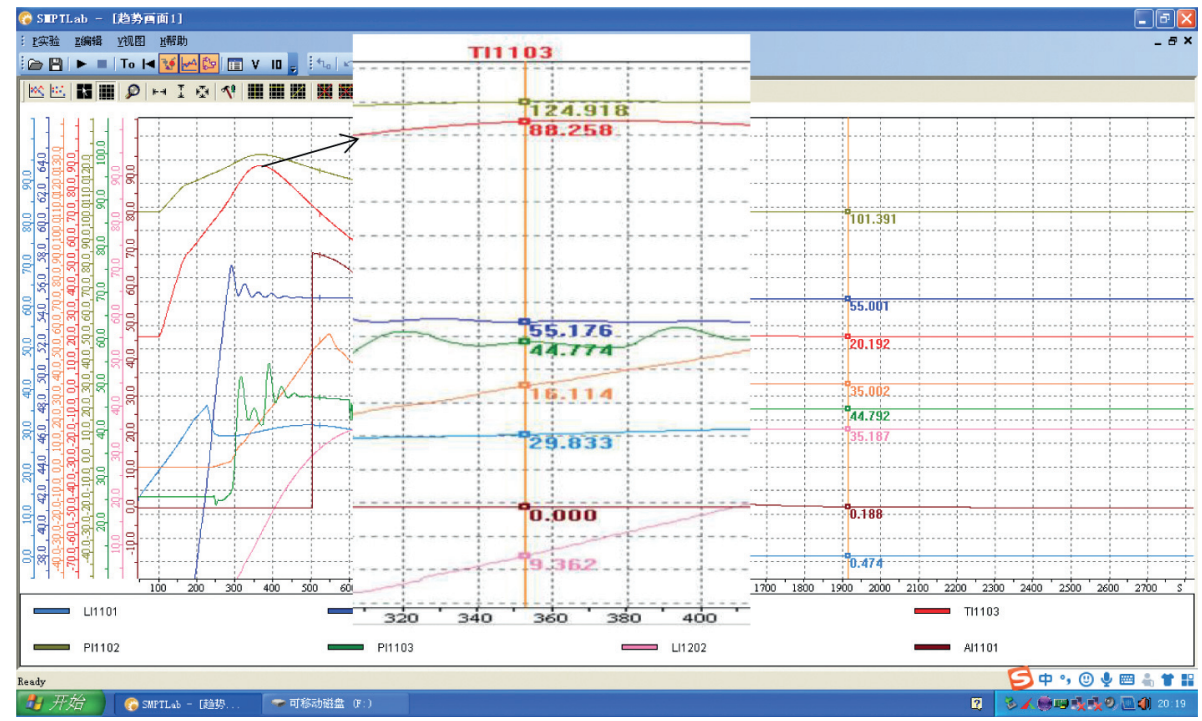

FIGURE 8: Original automatic disturbance rejection control iteration number 4000 of system trend graph.

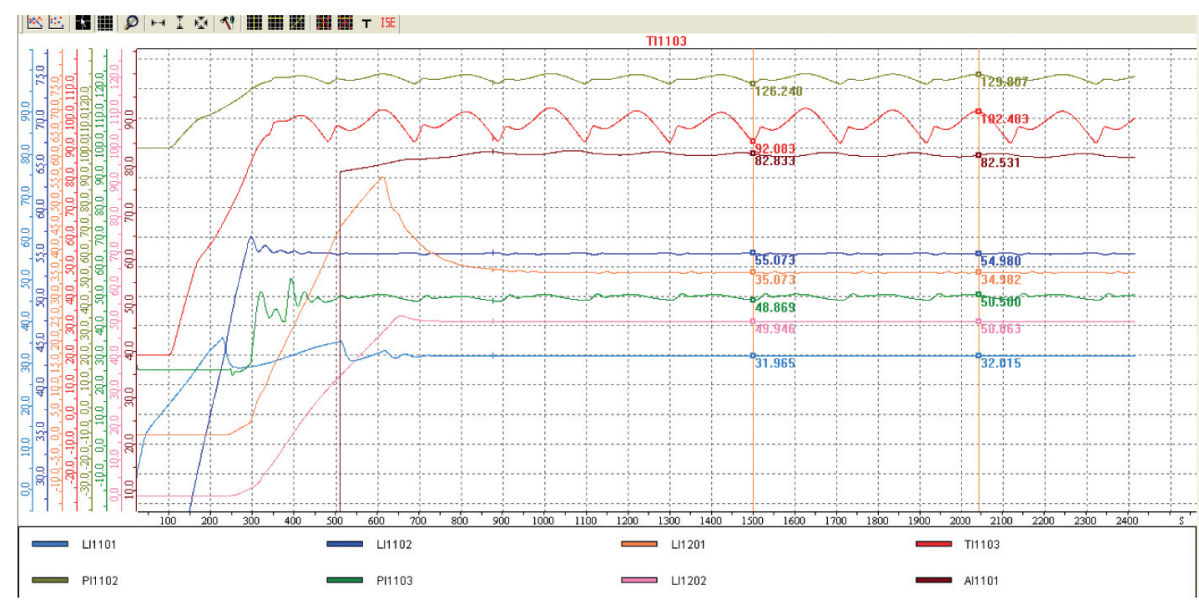

FIGURE 9: Smith forecast compensation system trend. 


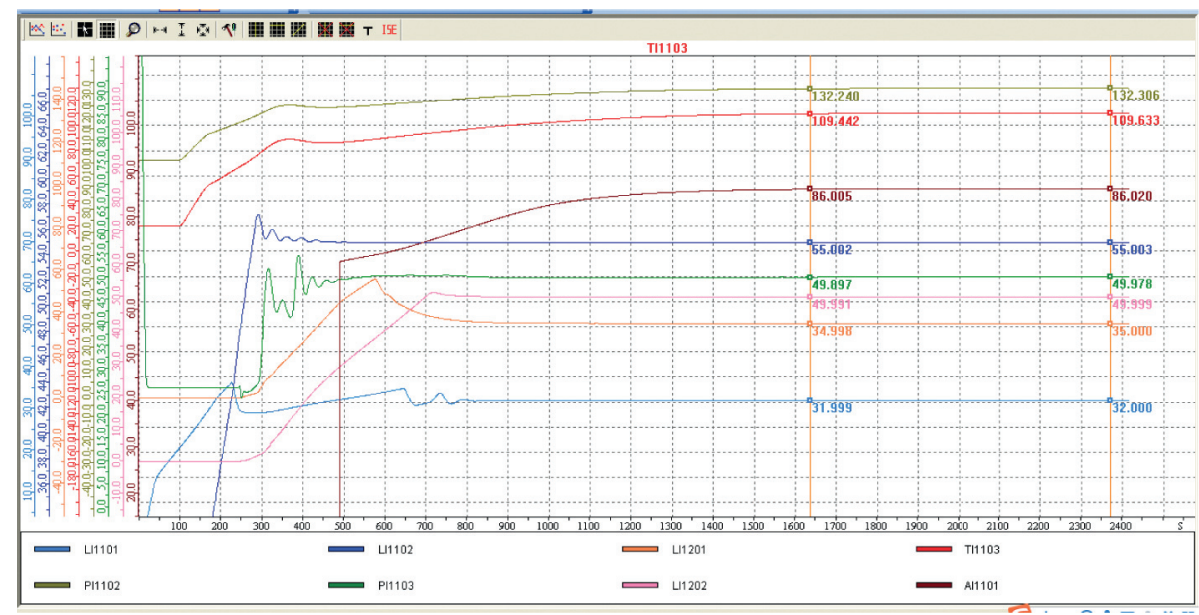

FIGURE 10: Trend graph of improved automatic disturbance rejection control.

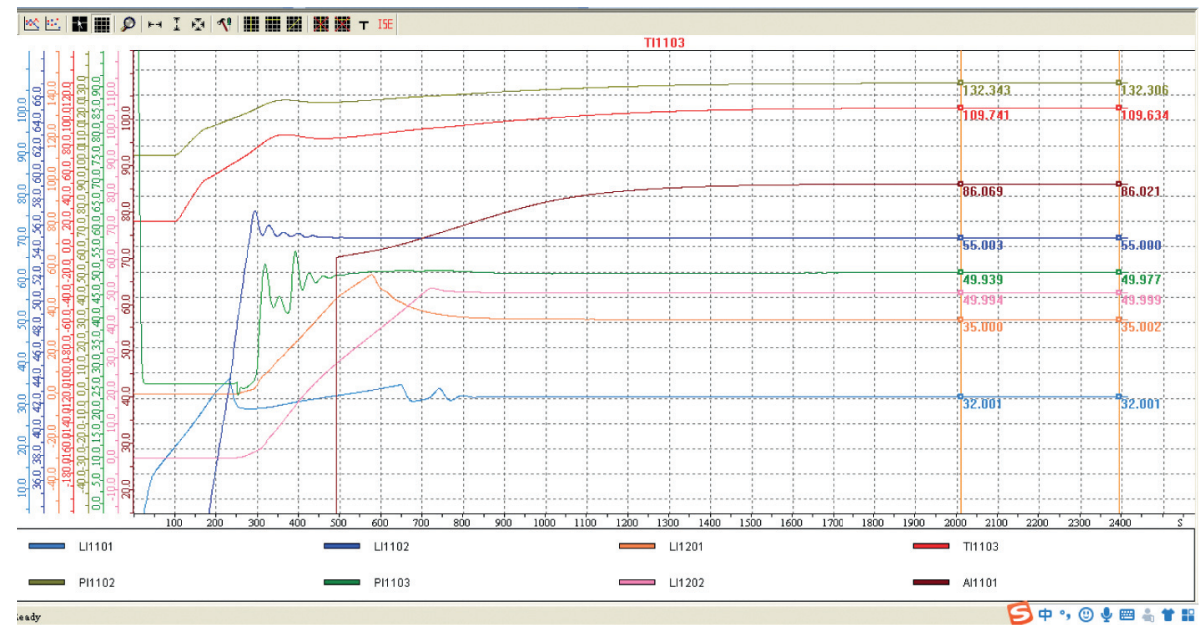

FIGURE 11: $k_{p}=200 ; k_{d}=60$.

low; the simulation trend curve is shown in Figures 11 and 13.

Figures 11 and 12 show that the $k_{d}$ size can be selected from 1 to 60. Comparing Figures 12 and 13, we obtain that the $k_{p}$ size of the nonlinear combination controller TIC1103 can be selected from 1 to 300; in addition, the stability value is insensitive to this $k_{p}$ size. The application of autodisturbance rejection technology requires high accuracy of parameters $k_{p}$ and $k_{d}$ [21]. The improved automatic disturbance rejection is less affected by the magnitudes of $k_{p}$ and $k_{d}$.

4.4. Robustness Verification of Changing Model Parameters. The engineering file for parameter modification is provided by Siemens. Applying the improved automatic disturbance rejection control method to the project file, we obtain the trend chart shown in Figure 14.

In Figure 14, the first load changed from initial 53 to 80 at $650 \mathrm{~s}$; the second load was 83 at about $1000 \mathrm{~s}$. The maximum reactor temperature was 109.613. TI1103 remained stable at 109.613 and continued after $1500 \mathrm{~s}$; pressure PI1102 was stable at 132.299 and remained stable and unchanged lasting after $1700 \mathrm{~s}$; the overshoot of both is about 0 . We further verify its robustness by comparing Figure 14 (control object after parameter modification) with Figure 6 (control object before parameter modification).

\section{Rules of Gain Selection}

The other parameters to be determined in the controller are participating in the work, and there is no need to set the size.

In the parameters tuning process, the setting of the differentiator's measured value of $n$ is selected from small to large according to the set value of the engineering object. The measured value of the observer was obtained by subtracting a set value $m$, and the difference between them is determined depending on positive or negative value of the sign function $\operatorname{sign}()$. If the difference is greater than 0 , the sign function value is 1 , and the parameter set by $m$ was taken from small to large, however, not greater than the temperature set value. 


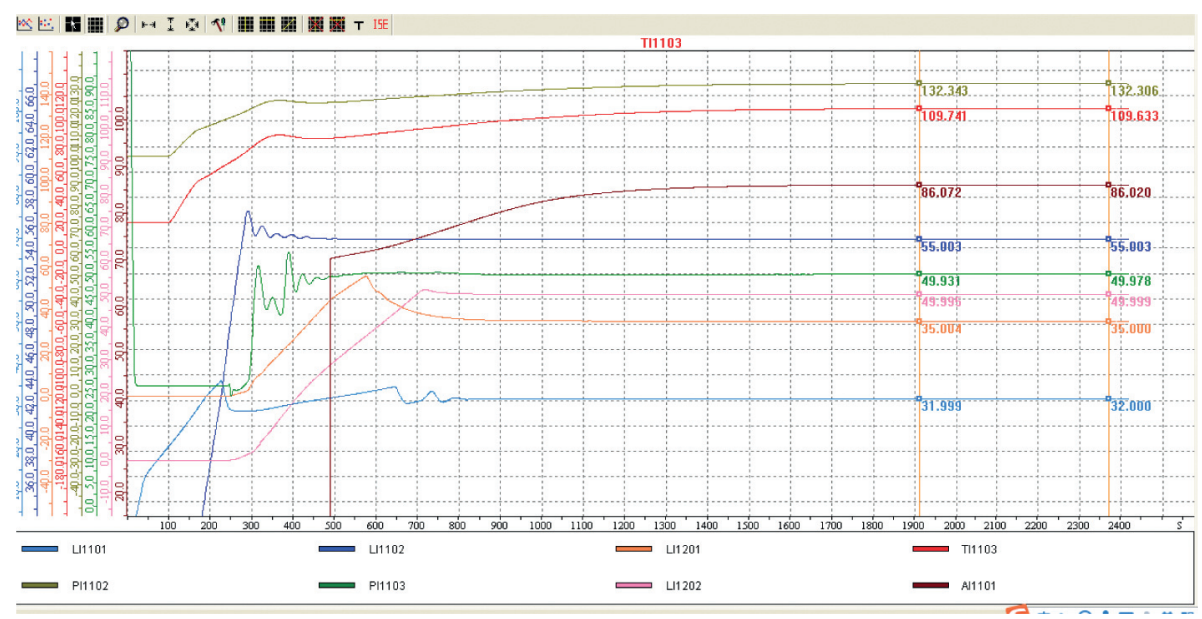

FIGURE 12: $k_{p}=200 ; k_{d}=20$.

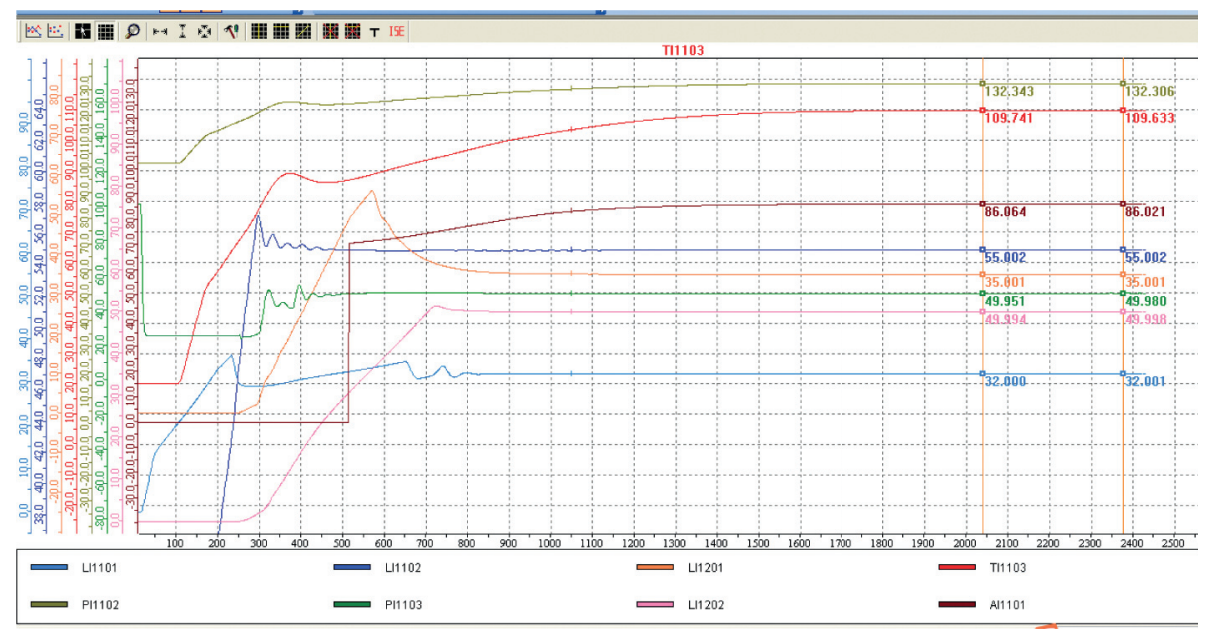

FIGURE 13: $k_{p}=300 ; k_{d}=20$.

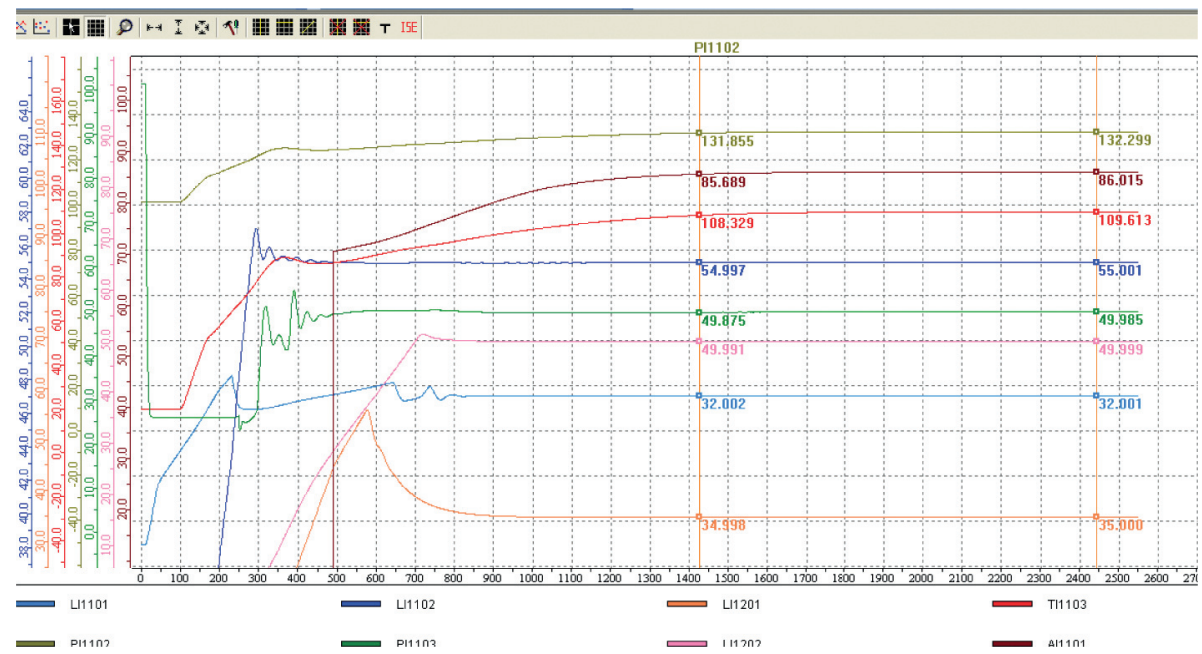

FIGURE 14: Improved automatic disturbance rejection control after modification of the control object model parameters. 


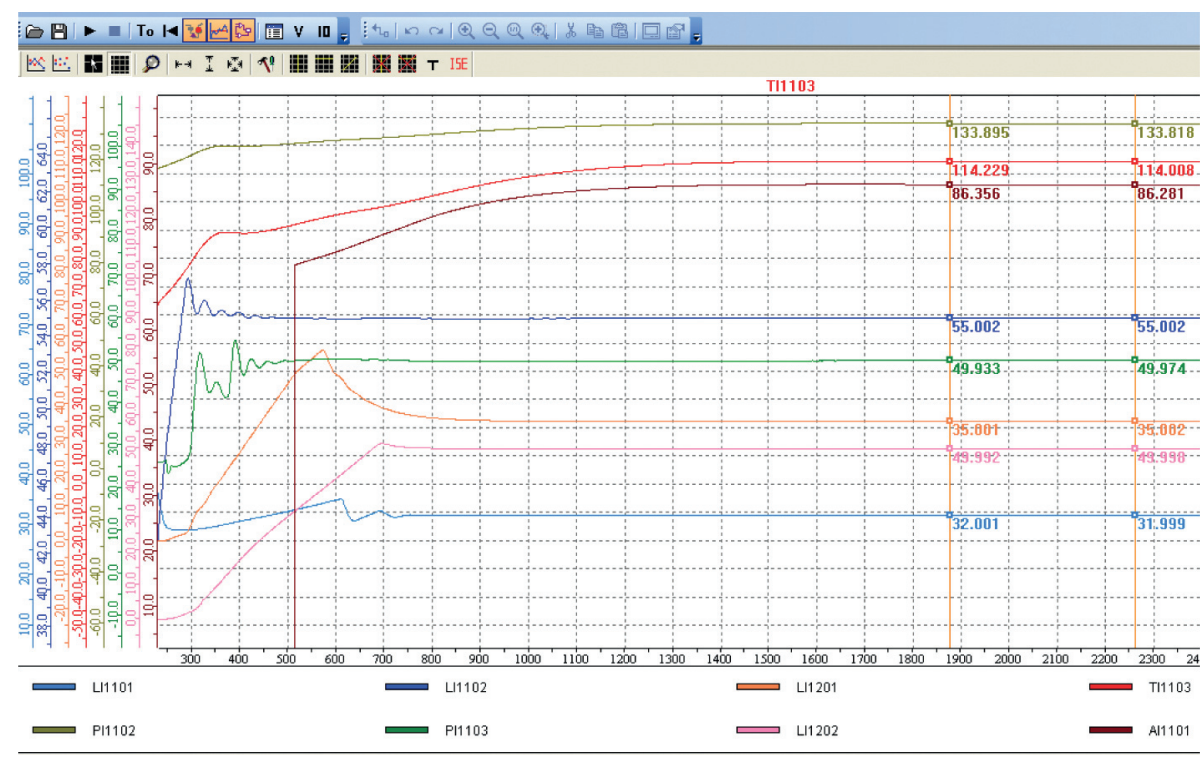

FIGURE 15: Improved automatic disturbance rejection control $b=0.058$.

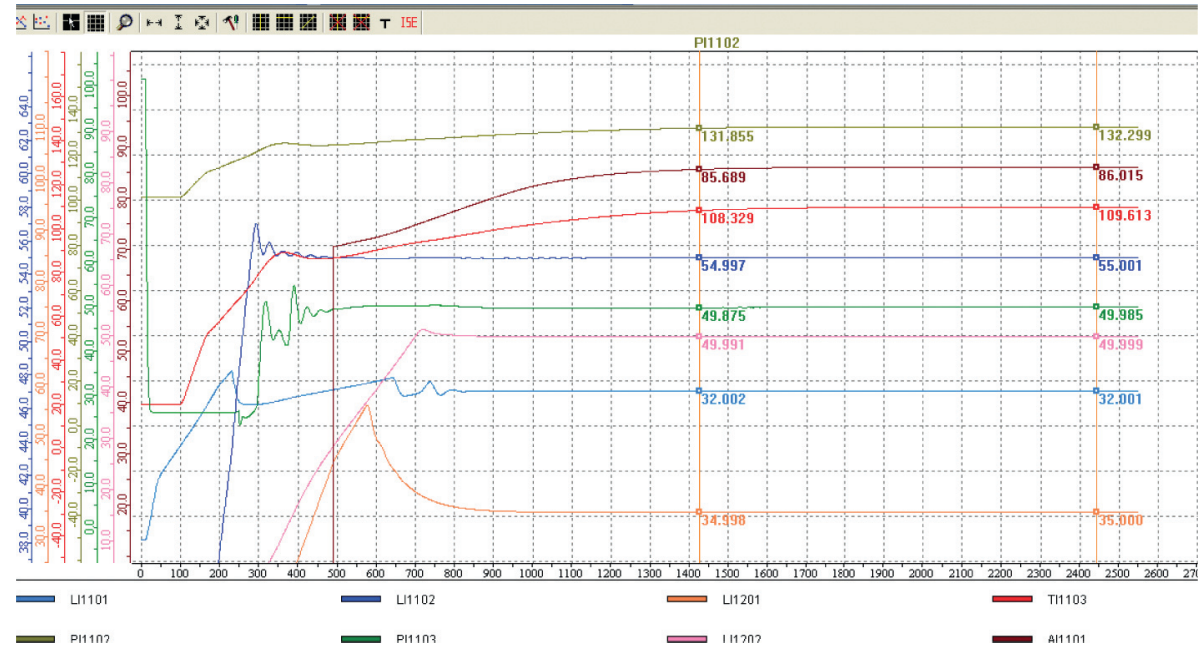

FIGURE 16: Improved automatic disturbance rejection control $b=0.06$.

The setting of other parameters in the differentiator and extended observer can be determined by the empirical formula and time scale method proposed by Han Jing-Qing.

After the differentiator and observer parameters are determined, the parameters of the nonlinear controller are adjusted. At this time, $b$ in the nonlinear controller plays a decisive role in suppressing the disturbance stability and the size of the stable value. The experimental comparison is shown in Figures 15 and 16.

The stable value can be determined by adjusting $b$; that is, the stable value of the reactor pressure and temperature decreases with increasing $b$.

It can be seen from TI1103 that the two trends are the same. However, the final stable result is different. In Figure 15, the reactor temperature TI1103 was stable at 114.008; the maximum deviation was 0.221 ; the overshoot was 0.001938; the pressure PI1102 was stable at 133.818; the maximum deviation was 0.077 ; the overshoot was 0.005754 ; the two remain stable and continue after 1400 s. In Figure 16, the reactor temperature TI1103 was stable at 109.613, and overshoot was 0.000985 , which is almost 0; pressure PI1102 was stable at 132.299, and overshoot was approximately 0.004235 ; the stability remained constant after $1700 \mathrm{~s}$. We observe that the overshoot for $b=0.058$ is higher than that for $b=0.06$; in addition, $b$ can adjust the final stable value.

\section{Conclusions and Prospect}

The ADRC technology is introduced into the process system, and the Siemens process control system is used on the SMPT-1000 platform to implement complex environment industrial system simulation and to verify the improved active disturbance rejection control principle. Compared 
with the Smith predictive compensation system longitudinally, the improved active disturbance rejection system has superior compensation and better overshoot for uncertain interference. Moreover, it achieves the expected stability faster and alleviates the damage of the oscillating signal to the reactor equipment. The components of the improved ADRC are the same as those of the original ADRC. In the composition relationship of the control part, the tracking differentiator and the extended observer in the improved ADRC can simultaneously collect signals. This improvement makes it immune to iterations, and the anti-interference time can be unlimited. However, the calculation results of the original automatic disturbance rejection tracking differentiator and extended state device are significantly affected by the number of iterations, resulting in limited signal tracking and internal and external disturbance compensation; that is, the anti-interference time is limited. In addition, the nonlinear combination of the original autodisturbance rejection requires higher accuracy of $k_{p}$ and $k_{d}$, which makes the performance of autodisturbance rejection largely dependent on $k_{p}$ and $k_{d}$; the improved autodisturbance rejection reduces the claimed accuracy of $k_{p}$ and $k_{d}$.

In actual systems, there may be problems of unmeasured speed and actuator saturation. In order to solve the problem of unmeasured speed, numerical differentiation and filtering on the position signal were performed in a previous study [24]; however, it will distort the real signal to a certain extent and reduce control performance. Therefore, a high-order sliding mode differentiator was proposed to estimate the velocity signal online and convergence analysis was performed on the estimation error and positioning error, respectively [25]. Wu et al. [26] proposed an adaptive output feedback control method for a five-degree-of-freedom tower crane; their method was specifically designed to introduce a virtual spring system to avoid speed-related feedback signals and to estimate the unknown cargo quality online through a new adaptive law. The results show that this method can effectively reduce the influence of uncertainty and interference and solve the problem that the speed signal cannot be directly measured in practical applications more effectively than in $[24,25]$.

Because the actual actuator can only produce limited control input, in order to avoid the problem of actuator saturation, a nested saturation controller is designed based on the cascade paradigm of the dynamic model [27]. In addition, Zhao and Gao [28] used Takagi-Sugeno fuzzy model based on saturation constraints to approximate the dynamic characteristics of bridge cranes and obtained the bounded results of tracking errors. Tong et al. [29] proposed a method based on the original dynamic model and accurately obtained the velocity signal with a well-designed observer, which is superior to the numerical differentiation operation of the measurable output variable. The controller is considered that the calculated control input is within the allowable range, thereby avoiding the saturation of the actuator and realizing the rapid positioning of the boom and the trolley and the suppression of the swing of the payload. Their solutions to the problems of unmeasurable speed and input saturation have useful reference values for the application of control objects in the actual system presented in this article. Moreover, these reference values can be considered in future research. The improved autodisturbance rejection will be more economical and practical in the actual industry.

The recycled pulp and paper industry has been rising in the world, but a large amount of organic waste is generated in the production, and the energy efficiency is low [30]. In the following work, the improved automatic disturbance rejection control is applied to the continuous reactor of the production to improve the stability, productivity, anti-interference, and energy efficiency of the continuous reactor and to alleviate the sludge environmental problems caused by the paper mill. Additionally, the internal circulation reactor used for integrated $\mathrm{CO}_{2}$ capture and power generation [31] and the reactor in the liquid indium-based chemical circulation system based on biomass gasification [32], respectively, will introduce improved automatic disturbance rejection control to further reduce the energy loss involved in the capture of carbon dioxide from the conversion of hydrocarbon and to maintain the temperature stability to achieve the optimum performance.

\section{Data Availability}

The data used in this article are original and reliable and are obtained through experiments.

\section{Conflicts of Interest}

The authors declare that they have no conflicts of interest.

\section{Acknowledgments}

This paper was supported by the National Natural Science Foundation of China (Grant/Award no. 51874010) and Research and Development of Explosion-Proof Permanent Magnet Frequency Conversion Integrated Machine for Mine, Key Research and Development Plan of Anhui Province (202004a05020080).

\section{References}

[1] A. Marin, J. A. R. Hernandez, and J. A. Jimenez, "Tuning multivariable optimal PID controller for a continuous stirred tank reactor using an evolutionary algorithm," IEEE Latin America Transactions, vol. 16, no. 2, pp. 422-427, 2018.

[2] A. Ate and A. Mohamed, "Controlling the temperature reactor based on raspberry PI system control," in Proceedings of the IEEE 2018 5th International Conference on Electrical and Electronics Engineering, pp. 215-218, Istanbul, Turkey, May 2018.

[3] A. Sinha and R. K. Mishra, "Control of a nonlinear continuous stirred tank reactor via event triggered sliding modes," Chemical Engineering Science, vol. 187, pp. 52-59, 2018.

[4] A. D. Kakule and P. Kerkar, "Implementation of temperature regulation and concentration tracking of CSTR with fuzzy controllers," in Proceedings of the Second International Conference on Intelligent Computings and Control Systems, pp. 758-764, Madurai, India, June 2018. 
[5] P. V. J. Rodrıguez and A. Arkkio, "Detection of stator winding fault in induction motor using fuzzy logic," Applied Soft Computing, vol. 8, no. 2, pp. 1112-1120, 2008.

[6] J. A. Oscullo and C. F. Gallardo, "Residue method evaluation for the location of PSS with sliding mode control and fuzzy for power electromechanical oscillation damping control," IEEE Latin america Transactions, vol. 18, no. 1, pp. 24-31, 2020.

[7] S. Durgadevi, K. Thirupura Sundari, D. Raaghavi, and R. S. Akshaya, "Comparative study of controller optimisation for CSTR using particle swarm optimization technique," in Proceedings of the ICEES 2019 5th International Conference on Electrical Energy Systems, Chennai, India, February 2019.

[8] S. Baruah and L. Dewan, "A comparative study of PID based temperature control of CSTR using genetic algorithm and particle swarm optimization," in Proceedings of the 2017 International Conference on Emerging Trends in Computing and Communication Technologies, Dehradun, India, November 2017.

[9] Y. R. Vladov and A. Y. Vladova, "Improved PID controller design for a two-stage technological workflow," IFAC Papers On Line, vol. 51, no. 30, pp. 226-230, 2018.

[10] M. Salehifarb, M. Moreno-Eguilaza, G. Putrus, and P. Barrasc, "Simplified fault tolerant finite control set model predictive control of a five-phase inverter supplying BLDC motor in electric vehicle drive," Electric Power Systems Research, vol. 132, pp. 58-66, 2016.

[11] Y. Wang and P. Yang, "Application of a control strategy based on PWA model in continuous stirred reactor," CIESC Journal, vol. 67 , no. 3, pp. 866-870, 2016.

[12] S. A. Senthil and S. Sundaramoorthy, "Optimal control policy for tracking optimal progression of temperature in a batch reactor-some insights into the choice of objective function," IFAC-PapersOnLine, vol. 51, no. 1, pp. 112-117, 2018.

[13] D. Mayer, H. Atzrodt, S. Herold, and M. Thomaier, "An approach for the model based monitoring of piezoelectric actuators," Computers \& Structures, vol. 86, no. 3-5, pp. 314-321, 2008.

[14] O. Alshammari, M. N. Mahyuddin, M. N. Mahyuddin, and H. Jerbi, "A neural network-based adaptive backstepping control law with covariance resetting for asymptotic output tracking of a CSTR plant," IEEE Access, vol. 8, pp. 2975529766, 2020.

[15] M. Skowron, M. Wolkiewicz, T. Eresa Orlowska-Kowalska, and C. T. Kowalski, "Effectiveness of selected neural network structures based on axial flux analysis in stator and rotor winding incipient fault detection of inverter-fed induction motors," Energies, vol. 12, no. 12, 2019.

[16] P. Rong and X. Guo, "Dynamic analysis and control of continuous reactor system," Journal of Electric Machines and Control, vol. 22, no. 8, pp. 99-105, 2018.

[17] D. Li and F. Gao, "Improved smith predictive decoupling control of compression refrigeration system based on disturbance observer," Journal of Shanghai Jiaotong University, vol. 53, no. 5, pp. 594-599, 2019.

[18] X. Qiao, F. Luo, and Y. Xu, "Robust PID controller design using genetic algorithm for wasterwater treatment process," in Proceedings of the Advanced information Management, Communicates, Electronic \& Automation Control Conference, Xi'an, China, October 2016.

[19] S. Saha, S. Rudra, T. Dasgupta, and M. Maitra, "Design of adaptive variable structure control law for industrial heat exchange process representing a class of non minimum process plant," in Proceedings of the 2016 IEEE Uttar Pradesh Section International Conference on Electrical, Computer and
Electronics Engineering (UPCON), Varanasi, India, December 2016.

[20] O. Alshammari, M. N. Mahyuddin, M. N. Mahyuddin, and H. Jerbi, "An advanced PID based control technique with adaptive parameter scheduling for a nonlinear CSTR plant," IEEE Access, vol. 7, pp. 158085-158094, 2019.

[21] H. He and L. Sun, "Asynchronous motor auto disturbance rejection control based on vector control," Journal of Motor and Control, vol. 23, no. 4, pp. 121-125, 2019.

[22] R. Dittmar, "Decentralized SISO active disturbance rejection control of the newell-lee forced circulation evaporator," IFAC-PapersOnLine, vol. 48, no. 8, pp. 409-414, 2015.

[23] A. Zhang and L. Yang, "Improvement of noise suppression for linear auto-disturbance control," Journal of Astronautics, vol. 40, no. 7, pp. 804-810, 2019.

[24] D. Chwa, "Nonlinear tracking control of 3-D overhead cranes against the initial swing angle and the variation of payload weight," IEEE Transactions on Control Systems Technology, vol. 17, no. 4, pp. 876-883, 2009.

[25] W. Chen and M. Saif, "Output feedback controller design for a class of MIMO nonlinear systems using high-order slidingmode differentiators with application to a laboratory 3-D crane," IEEE Transactions on Industrial Electronics, vol. 55, no. 11, pp. 3985-3997, 2008.

[26] Y. Wu, N. Sun, H. Chen, and Y. Fang, "Adaptive output feedback control for 5-DOF varying-cable-length tower cranes with cargo mass estimation," IEEE Transactions on Industrial Informatics, p. 1, 2020.

[27] R. Liu, S. Li, and S. Ding, "Nested saturation control for overhead crane systems," Transactions of the Institute of Measurement and Control, vol. 34, no. 7, pp. 862-875, 2012.

[28] Y. Zhao and H. Gao, "Fuzzy-model-based control of an overhead crane with input delay and actuator saturation," IEEE Transactions on Fuzzy Systems, vol. 20, no. 1, pp. 181186, 2012.

[29] Y. Tong, N. Sun, C. He, and Y. Fang, “Observer-based nonlinear control for tower cranes suffering from uncertain friction and actuator constraints with experimental verification," IEEE Transactions on Industrial Electronics, p. 1.

[30] M. Bakraoui, F. Karouach, B. Ouhammou, M. Aggour, A. Essamri, and H. El Bari, "Kinetics study of the methane production from experimental recycled pulp and paper sludge by CSTR technology," Journal of Material Cycles and Waste Management, vol. 21, no. 6, pp. 1426-1436, 2019.

[31] M. Osman, A. Zaabout, S. Cloete, and S. Amini, "Experimental demonstration of pressurized chemical looping combustion in an internally circulating reactor for power production with integrated $\mathrm{CO}_{2}$ capture," Chemical Engineering Journal, vol. 401, Article ID 125974, 2020.

[32] M. M. Sarafraz and F. C. Christo, "Thermodynamic assessment and techno-economic analysis of a liquid indium-based chemical looping system for biomass gasification," Energy Conversion and Management, vol. 225, Article ID 113428, 2020. 